International Journal of Managing Value and Supply Chains (IJMVSC) Vol. 3, No. 3, September 2012

\title{
THE Wine DisTRIBUTION SYSTEM IN THE DOMINICAN REPUBLIC: A QUALITATIVE APPROACH
}

\author{
Olga Murova ${ }^{1}$, Natalia Velikova ${ }^{2}$, and Tim H. Dodd ${ }^{3}$ \\ ${ }^{1}$ Department of Agricultural \& Applied Economics, Texas Tech University, Lubbock, \\ TX, USA \\ olga.murova@ttu.edu \\ ${ }^{2}$ Texas Wine Marketing Research Institute, Texas Tech University, Lubbock, TX, USA \\ n.kolyesnikova@ttu.edu \\ ${ }^{3}$ Texas Wine Marketing Research Institute, Texas Tech University, Lubbock, TX, USA \\ tim.doddettu.edu
}

\begin{abstract}
This research presents a case study of the wine distribution system of the Dominican Republic (DR). It focuses on the emerging wine market which is not a wine producing region, however represents a large and growing market for export of wine. Data were collected though in-depth interviews with major representatives of the $D R$ wine distribution system-importers, retailers, managers of restaurants, allinclusive resorts, and hotels. In addition, field observations were used as a mechanism of qualitative data collection. The findings show that almost all available wine in the DR is controlled by importers. Importers negotiate promotional costs, slot fees, and promotional budgets with the producers and provide credit to retailers. The Dominican Republic wine market operates in a highly competitive environment; Spain, Chile, Italy, and the United States are primary competitors on this market. Retail represents the biggest channel for sales of imported wines.
\end{abstract}

\section{KEYWORDS}

Wine supply chain, Dominican Republic, emerging markets

\section{INTRODUCTION}

Since the late 1980s, the world has witnessed globalization of many industries. Globalization is a process that came unavoidably due to many economic, political, technological, and social changes. Industries that offer goods or services experienced a shift toward international business. Today's consumers do not require face to face communication, as they can directly purchase goods produced in another part of the world through the Internet. Even perishable products produced in one country can be offered and delivered to consumers in another country. Flowers, for example, are being delivered to the United States from Columbia and can be purchased in Wal-Mart at an affordable price.

The wine industry is one of the most globalized industries in the world. Saturation of wine market has been outlined in the literature as one of the reasons for globalization of wine industry. Traditionally, wine has been viewed as a European product. Today, the European Union (EU) market is shrinking in terms of production and consumption. In 2010-2011 marketing year, the European Union produced 155,935 hectoliters of wine, which is 3.5\% lower than in the previous year [1]. Overall consumption of wine in the EU is stable, but per capita consumption declines. For comparison, wine consumption per capita in Europe has declined from 53 liters in 1991-95 to 44 liters in 2009 [1]. In order to keep stability in consumption, the EU is expanding its export markets in developed countries (US, Canada, and Japan) and BRIC

DOI: $10.5121 /$ ijmvsc. 2012.3301 
economies (Russia and China). Impacts of globalization in the wine industry are also seen in Asia. Asian countries such as Japan, Taiwan, Singapore, China, and Korea have increased their wine consumption significantly and represent potential export markets [2].

Globalization of wine industry led to the creation of production in the New World countries. In 1999, Rachman discussed differences in the level of consolidation in the Old World wine industry (mostly Europe) compared to the New World wine countries such as Australia, New Zealand, and South Africa. According to Rachman, in the Old World, wine is an agricultural product based on family traditions and the presence of appropriate conditions, such as the landscape, climate and soil for grape growing. In the New World, technology, in association with favorable and stable climatic conditions, is the main driver of wine production [3].

Globalization has fostered increased international competition between Old and New World producers [4]. In the Old World, wine production is still concentrated in the well-established producers, particularly France, Italy, and Spain, but without any growth. However, production of wine in the New World is increasing, particularly in the United States, Australia, Chile, Argentina, New Zealand, and South Africa. In 2010, France, Italy and Spain remained leaders in wine production. However, between 2007 and 2010 their overall production of wine decreased by $11.24 \%, 7.72 \%$, and $5.73 \%$, respectively. United States, Argentina, and Australia followed the three leaders in the production ranking for the same year. These three countries increased their production share within the same time period by $5.67 \%, 8.00 \%$, and $12.36 \%$, respectively [5]. The big three Old World producers have increased the value of their exports but their relative shares of the world trade went down, in contrast to the New World producers, who increased their market shares in exports dramatically [6]. Between 2007 and 2010, other New World countries such as South Korea, Peru, Slovenia, Ukraine, and Brazil each increased their exports by more than $260 \%$ [5].

The ultimate goal of all wine companies and corporations is to deliver increasing returns to their shareholders. Since most wine producers in developed markets operate in saturated market conditions, they look to mergers, acquisitions, joint ventures and other strategic arrangements as attractive ways to grow and to be highly efficient and responsive to dynamic changes in global markets [7]. One way for an industry to achieve competitive advantage is through the analysis of existing supply chain with consideration for local conditions within the global context.

\section{BACKGROUND LITERATURE}

The concept of supply chain is still urgent, timely, and ever-changing topic due its applicability to many industries, a variety of products, and its international context. To improve profitability and to confront difficult competition,companies are in search of effective ways to improve themanagement of the supply chain which plays an essential role for cost reduction and productivityincrease [8].

One of the classic ways to analyze supply chain is to apply Value Chain Analysis (VCA). The concept of the value chain was introduced by Michael Porter in his seminal work on competitive advantage [9]. The concept relates activities within and around the organization and translates them into strong points of an organization. According to Soosay et al., value chain analysis focuses on three key issues - first, the dynamics of information in the value chain; second, the creation and flow of value at each stage in the value chain; and third, the level of trust between shareholders [10]. Information flow in the value chain should be inclusive, transparent and responsive from final consumption back to primary production and input suppliers and back. Questions such as, "are there critical activities that would provide added value?", or "how the created value is shared along the chain? should be answered. Value chain analysis provides a diagnosis to reveal the opportunities for improvement at different stages in the value chain. 
Some researchers look at the Sustainable Value Chain Analysis (SVCA) which incorporates two methods - Value Chain Analysis and Life Cycle Analysis (LCA) [10]. This method allows determining the value that final consumers attach to environmentally harmful activities or to activities leading to sustainable use of resources.

In his article "The New Supply Chain Agenda" Paul Dittmann discusses five pillars that create the foundation of the supply chain concept [11]. These are: talent, technology, internal collaboration, external collaboration, and managing supply chain change. The author argues that the role of the modern supply chain executive has changed dramatically lately. Today's CEO must possess such qualities as global orientation, systems thinking, influential and inspiring leadership, technical and business skills. The benefits of supply chain technology can be huge when selected and implemented properly. As a general rule, larger companies implement more sophisticated technologies than smaller companies. The author cautions that people's issues are tougher than technical issues, so for new technology to create a benefit, people in a supply chain should accept and embrace the new technology.

Successful internal collaboration takes place when all departments including sales, marketing, logistics, and operations focus on the consumer. Internal cross-functional collaboration has been a hot topic for many years $[12,13,14]$. The most common cross functional problem between departments that exists today in a supply chain is to match supply with demand $[15,16$, 17]. Some researchers begin to differentiate between supply chain and demand chain. They define demand chain as an entity in its own right $[18,19]$. External collaboration contributes to excellence by bringing suppliers and consumers together to work out an agreement of sharing savings from joint improved efforts [11]. Superior performance is seen by firms with a customer value-focused culture [20].

Business firms operating in a global environment have to know how to manage risk in a global supply chain. Risk management requires accounting for the difference in culture, values, language and organizational behavior [21].

\subsection{Supply Chain in the Wine Industry}

Current research on supply chain in the wine industry applies and develops existing principles of general theory. Additional topics that are industry-specific, include: how to overcome barriers of supplying wine to traditionally non-drinking countries of the New World; how the new wine industry, from large to small producers, can capture authority on the global market; or how to incorporate sustainability into the wine supply chain.

Due to the globalization of the wine industry, new wine consuming marketsare emerging, including markets where wine has not been a traditional drink, for example the Asian market. Different marketing and supply strategies are applied within the Asian market. Some countries like China embrace new wine drinking culture with ease; while other countries such as Japan, Korea and Singapore adopt a special strategy of using cultural intermediaries to incorporate wine in their culture. In general, Asian countries have strong associations between culture, eating habits, and food preferences. Therefore, it is very difficult to alter an individual's food and beverage habits. Thus, it is important to understand the social and economic dynamics of the wine sector not only through the supply chain, resource ties and activity links [22, 23], but also through the role of cultural intermediary [24]. Rod et al. explored cultural intermediation in the wine markets of Japan and Singapore and stated that cultural intermediaries represent a bridge or link that facilitates a flow of specific knowledge about products and markets. Bourdieuinterpreted cultural intermediaries as those who engage in representing institutions, goods or services while mediating taste and consumption practices based on the needs of producers[25]. 
In the early 2000's, wine production in the New World countries was growing faster than wine consumption. Wine producers in these countries started expanding their export markets and capturing international market share. By 2010, the Southern Hemisphere's share of global wine production had increased by half since the early 1980s, and its share of global exports had risen from $1 \%$ to $27 \%$ at the same time [26]. The size of companies in the New World countries vary from large firms in Chile and South Africa listed as national or multinational, to medium and small wineries in New Zealand. Current research looks at the various aspects of capturing authority on the global market by improving information sharing amongst supply chain partners [27], the role of channel coordinators when exporting from one country to another [6], niche marketing and importers [28].

Improving the sustainable practices of supply chains has come to the forefront for many wineries around the world who adopt environmental practices. Therefore, an expanded view of sustainability in the wine industry can be provided by answering questions such as: how does implementation of sustainability practices improve firm performance outcomes, or how sustainable practices might provide a competitive advantage to wineries and their supply chains. The subject of the impact of environmental and/or social sustainabilityon supply chain characteristics in the food and wine industries have been addressed in the literature [29, 30,31].

Some specific factors of the wine industry must be considered when conducting supply chain research. Many industries have year-round sourcing, but wine production follows a rigid yearly cycle. Grapes are harvested once a year and bottling follows in a few months. Wineries must allocate production across many sales channels before demand is known. At this point, the problem of misallocation may arise and result in surpluses in some channels and lost sales opportunities in others. Postponement can be applied in such cases as a channel management tool. This management tool is applied to larger wineries that have export and private label channels. Cholette, whose research is based on California wineries, predicts that larger wineries will increase postponement practices in the near future [32].

Despite the general understanding of the importance of studying emerging markets of the New World, the academic literature and the industry reports focus mostly on developing wine producing countries, such as New Zealand, Chile, or China. In contrast, those countries that are not wine producing regions are often overlooked. However, these markets may be equally important. Even though they do not produce wine of their own, they may comprise lucrative markets for export.

One such market is the Dominican Republic. The country is not a wine producing region. Currently only a handful of local low quality wine brands are available in the Dominican Republic, so the vast majority of the market consists of imported wine [33]. It is, therefore, an important market to consider for wine marketers that are seeking export opportunities.As an effort to gain insight into this market, the current research focuses on the examination of the wine supply chain in the Dominican Republic. The importance of analyzing structures, processes and actions in the value supply management has been recognized in literature [34].

\section{Study ObJective}

The current studyaims to conduct an assessment of the emerging wine market of the Dominican Republic with the specific assessment of the wine distribution system.

\section{Methodology}

Because existing information on the topic under investigation is scarce, the researchers utilized inductive reasoning in designing the study. Given the inductive nature of this research, qualitative methodology emphasizing discovery and interpretation was determined most advantageous to collect a concentrated set of opinions on the topic [35]. 
Another reason for choosing qualitative methodology was the development of a culturallyappropriate research protocol - a strategy suggested by Harry Triandis[36]. The basic premise of this strategy is for researchers to reflect on the cultural reality being studied by taking into consideration emic (culture-specific) aspects of behaviors to be measured. Triandis suggested that in order to examine subjective culture (as opposed to objective culture, which refers to physical aspects such as pottery, architecture, art, etc.), it is best to begin with open-ended questions to elicit new themes, issues, and associations that are salient among the group members. These themes are then content analyzed in order to identify the most representative responses. This strategy has been widely used in socio-psychological research to identify Hispanic culture-specific values and norms [37]. Given its proven usefulness, the researchers based the current study on the Triandis's strategy and chose the following research methodsas the appropriate research protocol: (a) face-to-face in-depth interviewswith major representatives of the Dominican Republic wine distribution system, and (b) field observations.

Qualitative interviews have been categorized in avariety of ways, with many contemporary literature looselydifferentiating qualitative interviews as unstructured,semi-structured and structured [38]. Structured format interviews often produce quantitative data. Given the exploratory nature of the current project, semi-structured interviews were used.Semi-structured interviews aregenerally organized around a set of predeterminedopen-ended questions, with other questionsemerging from the dialogue between interviewer and interviewee(s). They are usually scheduled at a designated timeand location [38].

A set of in-depth interviews with major representatives of the Dominican Republic wine distribution systemwere scheduled in advance with the assistance of an in-country consultant who was recommended by the U.S. Agricultural Attaché for the Dominican Republic. The goal was to select major representatives from all distribution channels who can provide information that would add to the body of knowledge about the research topic. Specifically, the following groups were targeted: importers, retailers, managers of restaurants, all-inclusive resorts, and hotels. A quota of a minimum of two interviews per distribution channel was set and the quota was met. In total, the researchers conducted 22 interviews and interviewed 43 people. Table 1 shows the number of interviews and interviewees per distribution channel. Although representatives of the USDA Office of Agricultural Affairs in the Dominican Republic did not represent any particular distribution channel, they were interviewed as their contribution provided important insights to the overall picture of the wine distribution system in the country.

Table 1. Number of interviews and interviewees

\begin{tabular}{|l|c|c|}
\hline Channel & Number of interviews & Number of interviewees \\
\hline Importers & 4 & 10 \\
\hline Supermarket managers & 2 & 4 \\
\hline Liquor store managers & 3 & 5 \\
\hline All-inclusive resorts & 2 & 4 \\
\hline In-city hotels & 3 & 6 \\
\hline Restaurants & 2 & 6 \\
\hline Colmados & 3 & 4 \\
\hline Office of Agricultural Affairs & 3 & 4 \\
\hline Total & $\mathbf{2 2}$ & $\mathbf{4 3}$ \\
\hline
\end{tabular}

A structured interview script was designed based on the literature on the development of the emerging wine markets. The stimuli (interview questions) were standardized across all interviews. In addition, questions that were specific to a particular channel were added at the end of the interview. 
In order to further validate the obtained data from the interviews, the researchers conducted field observations in retail settings were wine is sold to consumers. The observations were incorporated to collect data on inventory, price points, and shelf allocations. A total of 8 observations were conducted - two at supermarkets, three at liquor stores, and three at colmados - small mom-and-pop independent grocery stores.

At the completion of the data collection, saturation of responses has been achieved. No new ideas or views emerged and adding more interviews or observations would have been likely to produce repetition of themes. Therefore, a total number of 22 interviews and 8 field observations were deemed sufficient for the purposes of this exploratory study.

Obtained data were transcribed and analyzed by threeresearchers who worked independently. The initial conclusions were developed and then cross-examined to ensure precision, a nuanced approach and credibility for the findings. The process offered a high-level researcher triangulation[39] and helped provide inter-coder reliability.Given the purpose of the study to conduct an assessment of the wine distribution system in the Dominican Republic, the findings below are presented to provide a description of each distribution channel, followed by the analysis of inventory and price points.

\section{FINDINGS}

\subsection{Major channels of distribution}

Dominican wine distribution system currently incorporates the following off-premise and onpremise channels:

Off-premise:

- $\quad$ Importers

- $\quad$ Supermarkets

- $\quad$ Liquor Stores

- $\quad$ Specialized retailers (colmados)

On-premise:

- $\quad$ All-inclusive resorts and hotels

- In-city and business hotels

- $\quad$ Restaurants/ bars

\subsubsection{Importers}

Almost all available wine in the Dominican Republic is controlled by importers. The Dominican Republic has five major importers that currently dominate the market: El Catador, S.A .(the largest importer of wine and beverages in the Dominican Republic; imports more than three quarters of the total wine market), Marcas Premium, S.A., Manuel Gonzalez Cuesta, Sucs C por A, Alvarez y Sanchez, C por A, and Vinos S.A. There are also a handful of smaller wine importers, but they represent a very small market share.

These businesses import wine from a variety of countries and regions and then distribute their products to retail outlets, resorts and hotels, or their own stores. Importers an also sell wine directly to consumers and their direct sales represent about $20 \%$ of the wine market in the Dominican Republic. Importers often feature their products through special events, such as showrooms, wine bars, and featured wine tastings, and provide valuable education and exposure to consumers.

Wine choices by importers tend to be based on quality, brand recognition, willingness of the wine producer to provide support, training, and promotional materials, and the overall relationship the brand establishes with the importers. 
Traditionally, most importers imported wine mainly from Spain. However, as preferences of consumers have changed, importers have also changed their allocation of imported wine inventory. Most interviewed imported reported that the market is stably dominated by wine from two majors regions - Spain and Chile. Depending on the importer, Spain and Chile are close competitors and hold roughly 30\% each of each importer's inventories. Other major competitors on the market are Argentina,the United States,France, Italy, and Australia.

Interviews revealed that wine from Chile and Argentina is perceived as trendy and becoming more popular, particularly because these countries offer high quality products at cheaper prices and lead aggressive promotional strategies with many tastings and advertisements.

The percentage between on-trade and off-trade sales has changed significantlyfor most importers due to the demand growth in the retail sector. In the past, the largest importerEl Catador, for example, experienced about $75 \%$ on-trade sales and $25 \%$ off-trade sales. Today, El Catadornotes that on-trade and off-trade sales are about $50 \%$ each, most of which occurs within supermarket chains, such as Nacional, which is its principal client.

\subsubsection{Retail}

Retail is by far the biggest channel as the vast majority of Dominican consumers buy wine for personal consumption or as a gift at supermarkets or liquor stores. Previous research noted that supermarkets in the Dominican Republic are growing in number and size and represent about $30 \%$ of the retail market. In 2001, there were over 600 supermarkets and mini marts in the Dominican Republic, most of which were located in Santo Domingo and Santiago, and the number of supermarkets continues to grow nationwide today [40]. Since supermarkets reach mostly the middle and upper classes with higher incomes and remain the main means to distribute most imported food products in the Dominican Republic, these are definitive targets for wine.

Lower-income Dominicans tend to purchase their food and beverages at colmados. Although supermarkets tend to offer better selection and product variety, many lower-income people purchase groceries at colmados because of proximity, quantity of items needed, and personal relationships with the people who run the colmados. Field observations revealed that wine can be found in these types of stores but with low variety and lower quality. High-end wines are scarcely represented at colmados and are sold at higher prices than at supermarkets and liquor stores. Consumers report that they would occasionally buy wine at these outlets, mainly for convenience reasons.

\subsubsection{All-inclusive Resorts and Hotels}

All-inclusive resorts represent a little less than $30 \%$ of the wine market in the Dominican Republic. Numerous resorts are scattered along the coastline of the Dominican Republic. These resorts are an important source of wine sales. As tourism has increased dramatically over the last decade, most visitors to these resorts are international travelers from European countries and North America, with a few local Dominicans visiting as well. The resort's price range and clientele affect the type of wine available to visitors.

In-city and business hotels, on the other hand, represent only about $2 \%$ of the Dominican wine market. These hotels tend to sell wine served only at wedding receptions and banquets, unless the hotels also operate high-end restaurants. These businesses tend to purchase their wine from local importers.

\subsubsection{Restaurants}

Restaurants represent about $20 \%$ of the wine market in the Dominican Republic. Although restaurant sales have declined lately relative to off-premise sales at supermarkets and liquor stores, restaurants (particularly upscale restaurants) still represent an important channel for wine 
sales in the Dominican Republic. Restaurants sell wine by the glass and by the bottle. However, by-the-glass programs are rare and not very popular. In the Dominican culture, orders in restaurants usually include ordering a bottle of wine, rather than buying wine by the glass. Consumers can find wine at a variety of restaurants, although better wine quality, variety, and availability are usually found at upscale restaurants. Overall, restaurants have the best potential for high-end wine sales in the Dominican Republic.

\subsection{Analysis of Inventory and Price Points}

\subsubsection{Supermarkets}

Since retail represents one of the major channels of the wine distribution system, field observations were conducted on retailer shelf allocation and price points. Researchers observed that retailers organize their wine inventory mainly by wine color and by the country of origin, with the largest portion of shelf allocation given to reds and to Spanish wines. For example, Nacional, one of the largest supermarket chains in the country, allocates six aisles (out of 8 total wine aisles) to red wine. Of these six red wine aisles, two aisles are Spanish wines, two aisles are Chilean wines, one aisle is French/Italian wine, and one aisle is reserved for wines from the U.S., Argentina, and other regions. Only one aisle is allocated for white wines, and another aisle is split between rosé wines, which represent about $2 / 3$ of the wines in the aisle and alternative packaging wines, which represent another $1 / 3$ of the wines in the aisle.

It was also observed that wine is packaged mostly in traditional $750 \mathrm{ml}$ glass bottles. Tetrapack and plastic bottles are present in retail outlets, but this packaging represents roughly less than 5\% of the total wine assortment in supermarkets / liquor stores. Small, six-pack or $180 \mathrm{ml}$ bottles were scarcely represented, and it was indicated by supermarket beverage managers that these smaller packing options are sold mostly during lunchtime due to the beverage size and screw top convenience. Overall, however, consumers feel very resistant about screw tops, and this type of closure is virtually not present in the market. Interviewees indicated that Dominican consumers feel very strongly about traditional cork closures.

Researchers examined wine prices in retail settings and noted that a wide price range is evident: from 200 pesos (approx. US\$5.14) on the lower end to as high as 3,000 pesos (approx. US\$77.12) on the higher end.

The most common price for a daily consumption red wine is around 400 pesos (approx. US\$10.28). Retailers who price wine over 400 pesos/bottle experience a noticeable decline in sales. All retailers interviewed noted that within the last year, they experienced a noticeable decrease in overall profit sales, but not in volume sales. Nacional, for example, indicated that within the last year, their wine sales increased in volume by $33 \%$. However, these wines tended to be priced cheaper.

Dominican retailers are allowed to purchase wine directly from the producer, with no involvement of wine importers. Grupo Ramos, for example, imports certain brands directly to its chain with exclusive rights to represent these brands. At the same time, however, the company also carries most known brands, which they purchase through importers. Retailers typically purchase through importers those brands that are well represented in the market in order to remain competitive with other retailers. For example, $70 \%$ of Grupo Ramos's inventory is Spanish wines because of thewell established business contacts in Spain. The other $30 \%$ of their inventory includes wine from other regions - mostly those brands that are widely available in the market.

When importing wines directly from producers, retailers indicated that they tended to mark-up wines as much as $60 \%$. Wines purchased through an importer, however, tended to only have a 
price mark-up of 25-30\%. Based on the results of the interviews, researchers estimated the following commercialization margins in the Dominican Republic:

- Importers: $40 \%-50 \%$

- $\quad$ Retailers: $25 \%-30 \%$

- Restaurants: $100-300 \%$

\subsubsection{All-Inclusive Resorts and Hotels}

Over $80 \%$ of hotels in the Dominican Republic are all-inclusive businesses (resorts). These resorts vary considerably in clientele, cost, and amenities offered, which is reflected in the wines carried. For example, researchers found upscale resorts typically have extensive wine lists with wines from the major wine regions of the world. On the other hand, many of the midrange resorts offering all-inclusive food and beverages only carry a few wines.

Resorts import wines directly and almost exclusively in bulk from wine producers mainly in Spain, and these wines tend to be priced between US\$.80 and US\$3.00 per liter. Bottled wine is also imported and available through "al-a-carte" menus. However, this option is not very popular among patrons of all-inclusive resorts.

Interviewees noted that most patrons drink cocktails as part of their all-inclusive packages but often order a bottle of wine when they dine at the restaurants. Ordering a bottle of wine not included in the package, however, is typically seen as a special occasion.

The other $20 \%$ of the total hotel market in the Dominican Republic is comprised of in-city hotels. In-city hotels' major clientele includes in-house guests, local business people, wedding receptions, and banquets. Most in-city hotels purchase wine through local importers. Legally, hotels are allowed to purchase wine directly from wine producers. However, producers require full order payment in advance, while local importers provide credit, thus creating more advantageous conditions for hotels. In-city hotels often partner with local wine importers in an effort to educate consumers about wine. For example, some in-city hotels featurepromotional tastings and manage their own wine club, featuring live music and tastings on Friday nights. In the past, in-city hotels tended to add a substantial mark-up to wine prices, but the trend now is to lower the mark-up to attract more local customers.

\subsubsection{Importers}

Orders are placed through direct contact with supermarkets and liquor stores, and importers then pay slot fees to retailers to carry their brands. Importers indicated that they negotiate promotional costs with the producers and value those producers who invest in promotional materials and point-of-sales and continuously provide promotional campaigns for their products. Slot fees, as well as promotional budgets, can be negotiated and are usually paid by wine producers as well.

Purchasing options between retailers, importers, and producers have created double competition in the market since retailers can buy directly from both importers and producers. Producers require direct pre-payment for their products, whereas importers provide credit. As a result, although supermarkets, hotels, and restaurants can import directly from producers, most utilize importers because of attractive credit lines they offer.

\subsubsection{Restaurants}

Wine options and pricing at restaurants vary by restaurant and clientele. It was found that highend restaurants tend to be the primary carriers of wine, particularly more expensive wine, while restaurants in the mid-price and low-price range place little emphasis on wine. Moderately priced restaurants, for example, tend to carry relatively cheap Spanish or Chilean wines and overall provide only a very few brands for their customers to choose. 
Wine sold by the glass is dominated by wine from Chile and Spain, but by-the-glass programs are typically not very popular because they are perceived as expensive.

Most interviewees reported that dry red wine by far is the most preferred wine by the Dominican consumer. Some restaurant managers, however, indicated that during the last fewyears, they have noted a rapid growth in the consumption of sparkling and rosé wines. Future trends, they noted, would depend on the tastes and options available from importers.

\section{LIMITATIONS}

The researchers encountered a few problems while implementing the current project. Even with the strong support of the funding agency's (USDA) Office of Agricultural Affairs in the Dominican Republic, securing interviews with some of the target groups was challenging. The researchers used the assistance of an in-country consultant who had strong networking relationships within the industry and scheduled interviews well in advance. A few scheduled interviews, however, have been cancelled and the researchers were not able to reach the targeted number of interviews.

Possible reasons for the cancellations could be managers' and importers' busy daily schedules. No direct financial benefit resulting from the interviews could be another possible reason for challenges associated with the scheduling the interviews.

It is important to note, however, that the in-country consultant was persistent and was able to reschedule most cancelled interviews to another time. Overall, the researchers met with the major importers and beverage managers covering all wine distribution channels, including retail, restaurant, all-inclusive resorts, and hotels. At the completion of the two visits to the Dominican Republic, the analysis of the interviews revealed that saturation of responses has been achieved. Adding more meetings would have been likely to produce repetition of information or themes. Therefore, the number of the fulfilled interviews was deemed sufficient for the purposes of this project.

\section{ACKNOWLEDGEMENTS}

The authors would like to thank the United States Department of Agriculture (USDA) Foreign Agricultural Service who provided a grant through its Emerging Markets Program to assess the Dominican Republic wine market.

\section{REFERENCES}

1. USDA Foreign Agricultural Service (2011). Wine Annual Report and Statistics GAIN Report \# IT1105, prepared by J. Dever, approved by J. Dever, March 1.

2. Lee, K. (2009). Is a Glass of Merlot the Symbol of Globalization? An Examination of the Impacts of Globalization on Wine Consumption of Asia. International Journal of Wine Business Research, 23(3), 258-266.

3. Rachman, G. (1999). Christmas Survey: Terroir and Technology. THe Economist, 353(8150), 92-97.

4. Bernetti, I., Casini, L., \& Marinelli, N. (2006). Wine and globalisation: Changes in the international market structure and the position of Italy. British Food Journal, 108(4), 306-315.

5. California Wine Export Program (CWEP) (2011). World Vineyeard, Grape and Wine Report. Retrieved on August 13, 2012 from http://calwinexport.com

6. Tipples, R. \& Furgala, J. (2010). Cottesbrook Wines? Hiccups in the Supply Chain from New Zealand to the United Kingdom, Supply Chain Forum, 11(1), 76-84.

7. Arno, A. (2002). Globalization of the wine industry. Retrieved from http://www.winebusiness.com/wbm/?go=getArticleSignIn\&dataId=16088

8. Nakhla, Z., \& Akaichi, J. (2010). Intensification of the supply chain by the storing of trajectories data, International Journal of Managing Value and Supply Chains, 1(1), 1-13 
9. Porter, M.E. (1985). Competitive Advantage: Creating and Sustaining Superior Performance, Free Press, New York, N.Y.

10. Soosay, C., Fearne, A. \& Dent, B. (2012). Sustainable Value Chain Analysis - a Case Study of Oxford Landing from "Vine to Dine". Supply Chain Management: An International Journal, 17(1), 68-77.

11. Dittmann, J. P. (2010). The New Supply Chain Agenda. Retrived on August 14, 2012 from http://www.worldtradewt100.com

12. Barki, H., \&Pinsonneault, A. (2005). A model of organizational integration, implementationeffort and performance. Organization Science, 16, 165-179.

13. Kahn, K. B., \&Mentzer, J. T. (1998). Marketing's integration withother departments. Journalof Business Research, 41, 53-62.

14. Luo, X., Slotegraaf, R. J., \& Pan, X. (2006). Cross-functional'coopetition': The simultaneousrole of cooperation and competitionwithin firms. Journal of Marketing, 70, 67-80.

15. Alderson, W. (1958). The Analytical Framework for marketing. In D. Duncan (Ed.), Proceedings: Conference of Marketing Teachers from Far Western States, University of California, Berkley, pp.15-28.

16. Jüttner, U., Christopher, M., \& Baker, S. (2007). Demand chain managementIntegratingmarketing and supply chain management. Industrial MarketingManagement, 36, 377392.

17. Srivastiva, R. K., Shervani, T. A., \& Fahey, L. (1999). Marketing, business processes and shareholder value: An organizationallyembedded view of marketing activities and thediscipline ofmarketing. Journal of Marketing, 63, 168-179.

18. Langabeer, J. \& Rose, J. (2001).Creating Demand Driven Supply Chains.Chandos Publishing, Oxford.

19. Walters, D. \& Rainbird, M. (2004). The Demand Chain as an Integral Component of the Value Chain. Journal of Consumer Marketing, 21(7), 465-475.

20. Slater, S. F. (1997). Developing a customer value-based theory ofthe firm.Journal of theAcademy of Marketing Science, 25, 162-167.

21. Cross, B. \& Bonin, J. (2010). How to Manage Risk in a Global Supply Chain. Ivey Business Journal, 74(6), 1-18.

22. Hảkansson, H. \&Johanson, J. (1992). A model of industrial networks. In Axelson, B. and Easton, G. (Eds.), Industrial Network: A New View of Reality, Routledge, London.

23. Bouzdine-Chameeva, T. \& Ninomiya, M. (2011). Bordeaux Natural Wines in the Japanese Market: Analysis of Supply Chain System Indolence. Supply Chain Forum, 12(2), 70-82.

24. Rod, M., Ellis, N. \& Beal, T. (2012). Discursive Constructions of the Role of Cultural Intermediaries in the Wine Market of Japan and Singapore. Qualitative Market Research: An International Journal, 15(2), 128-147.

25. Bourdieu, P. (2000). Distinction: A social critique of the judgement of taste. Trans. RichardNice, Cambridge, MA: Harvard University Press

26. Sumner, D.A. (2010). The World of Wine: Economic Issues and Outlook. Agricultural And Resource Economics Update, Giannini Foundation of Agricultural Economics, University of California, 13(6), 1-16.

27. Forbes, S.L. \& Cohen, D.A. (2010). The dissemination of Information Amongst Supply Chain Partners - A New Zealand Wine Industry Perspective. Supply Chain Forum, 11(1),56-63.

28. Toften, K. (2010). Niche Importers and the Role of Commitment in Supply Chains: An Exploratory Study. Supply Chain Forum, 11(2), 87-92.

29. Thach, L. (2002). Social sustainability in the wine community: managing for employee productivityand satisfaction, Wine Business Monthly, July. Available at www.winebusiness.com

30. Maloni, M. and Brown, M. (2006).Corporate social responsibility in the supply chain: anapplication in the food industry, Journal of Business Ethics, 68(1), 35-52.

31. Pullman, M. E., Maloni, M.J. \& Dillard, J. (2010). Sustainable Practices in Food Supply Chains: How is Wine Different? Journal of Wine Research, 21(1), 35-56.

32. Cholette, S. (2010). Postponement Practices in the Wine Industry: Adoption and Attitudes of California Wineries. Supply Chain Forum, 11(1), 4-14. 
33. Beverage Industry Today. (2008). Dominican Republic wine news. Retrieved from http://beverages.einnews.com/archive/wines

34. Zelewski., S. \&Jene, S. (2011). Fairness: A challenge for the distribution of cooperation gains in value chains. International Journal of Managing Value and Supply Chains, 2(1), 1-20

35. Belgrave, L. L., Zablotsky, D., \& Guadagno, M. A. (2002). How do we talk to each other? Writing qualitative research for quantitative readers.Qualitative Health Research, 12(10), 1427 1439.

36. Triandis, H. C. (1972). The analysis of subjective culture. Oxford, England: Wiley-Interscience

37. Marin, G., \& Marin, B. V. (1991). Research with Hispanic populations (Vol. 23). Newbury Park, CA: Sage Publications, Inc.

38. DiCicco-Bloom, B. \& Crabtree, B.F. (2006). The qualitative research interview. Medical Education,40, 314-321

39. Wallendorf, M. and Belk, R.W. (1989). Assessing trustworthiness in naturalistic consumer research, in Hirschman, E. (Ed.), Interpretive Consumer Research, Association forConsumer Research, pp. 69-83

40. Mendez, W. A. (2002). USDA Foreign Agricultural Service, GAIN Report.Dominican republic retail food sector report (DR2032). Retrieved from http://www.fas.usda.gov/gainfiles/200211/145784622.pdf

\section{Authors}

Olga I. Murova (olga.murova@ttu.edu) received her Ph.D. from Mississippi State University. Currently she serves as an Assistant Professor of Agricultural \& Applied Economics at Texas Tech University. Her research interests include international development and trade, agribusiness management, production efficiency, and rural development. She is a member of the Blue Ribbon Panel on Economic Opportunities in Rural Communities of theCouncil on Food, Agricultural and Resource Economics (C-FARE). C-FARE is a national council whichhelps agricultural economists contribute to private and public sector decision making on issues importantto agricultural, rural, environmental and food safety.She is also a member of the Southern Agricultural Economics Association and the American Association of Wine Economists. She served as a reviewer for several professional journals, including EconomicDevelopment Quarterly Journal and Educational Economics Journal.

Natalia Velikova (n.kolyesnikova@ttu.edu) holds a joint appointment as an Assistant Professor in the Departmental of Nutrition, Hospitality, and Retailing at Texas Tech University and the Associate Director of the Texas Wine Marketing Research Institute. Her research interests include wine marketing, wine consumer behavior, and wine tourism. She also teaches courses in Wine Marketing and Wine Tourism in the College of Human Sciences at Texas Tech University. Natalia serves as a reviewer for several hospitality and wine business peer-review journals and often delivers presentations of her research to the wine industry professionals.

Tim H. Dodd (tim.dodd@ttu.edu) is the James and Kailee Young Regents Professor of Restaurant Hotel Management Department, and Director of the Texas Wine Marketing Research Institute at Texas Tech University. He also serves as the Associate Dean of Operations in the College of Human Sciences. Dr. Dodd has worked with the New Zealand grape and wine industry and served as President for the Texas Wine and Grape Growers Association. His research focuses on wine tourism and consumer behavior and he is an executive board member of the International Journal of Wine Business Research and the Journal of Hospitality and Tourism Research. He has published numerous articles

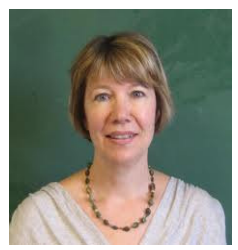
concerning wine marketing and winery tourism.
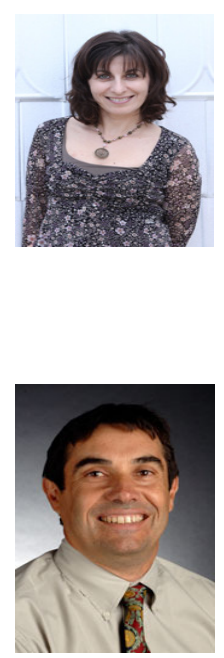